\title{
Os estudos sobre o Ciclo Confederativo e a história da integração latino-americana no século XIX
}

\author{
The studies about the Confederative Cycle and the latin american \\ integration history in the 19th century
}

\section{DIRCEU JUNIOR CASA GRANDE ${ }^{1}$}

Os esforços de integração das nações latino-americanas ocorreram imediatamente após os processos de independência das colônias da América e ficaram conhecidos como Ciclo Confederativo Latinoamericano. Fortemente influenciado pelas anfictionias europeias, o ciclo reuniu as nações recém emancipadas pela primeira vez no Congresso do Panamá, em 1826. Apesar das intenções integracionistas, malogrou precocemente diante de inúmeros conflitos entre os países, da resistência de grupos locais, das pressões dos Estados Unidos, entre outros fatores. Os objetivos deste trabalho são descrever os principais aspectos e elementos que configuraram o Ciclo Confederativo e analisar os estudos sobre o tema da integração latino-americana a partir da perspectiva singular do historiador mexicano, Gérman Adolfo de la Reza.

Palavras-chave: : Integração. Independências. Confederativo. Anfictiônico. América Latina

\section{ABSTRACT}

The integration efforts of the Latin American nations occurred immediately after the independence processes of the American colonies, known as Latin American Confederative Cycle. Strongly influenced by the European amphictyonies, the Cycle gathered the newly independent nations for the first time at the 
Panamá Congress, in 1826. Despite the integrationist intentions, it failed early in the face of several conflicts between the nations, concerning the local groups' resistance, the United States pressure, among others. This study aims at describe the main aspects and elements that configured the Confederative Cycle and analyzing the studies about the Latin American Integration theme from the singular perspective of the Mexican historian, Gérman Adolfo de la Reza

Keyword: Integration. Independences. Confederative. Amphictyonic. Latin America Palavras. .

\section{Introdução}

Os estudos sobre o Ciclo Confederativo latino-americano do século XIX apresentam a natureza complexa dos esforços de integração de povos e nações no ocidente (REZA, 2012, 2015). Tais movimentos revelam muito mais do que as intenções dos líderes dos países em formalizar tratados de união e liga em benefício da paz e da cooperação internacional. As complexidades desses tipos de ações políticas nos ajudam a perceber nos movimentos latino-americanos os elementos que informam suas origens, estratégias e dinâmicas. Diferentes pesquisas tem nos ajudado a compreender as ações unionistas na América vinculando-as aos movimentos anfictiônicos da antiguidade e da Europa dos séculos XVII e XVIII. As relações existentes entre esses movimentos de diferentes épocas estão entre as principais contribuições do historiador mexicano Gérman Adolfo de la Reza²

O processos integracionistas ocidentais, segundo Reza, remontam a Idade Antiga, mais precisamente ao período de formação da civilização helenística quando, segundo a lenda, Anfictião, filho de Prometeu, ensejou a união das cidades gregas com o objetivo de garantir a paz e a segurança dos povos a partir das assembleias anfictiônicas, como ficaram conhecidas as reuniões de nações daquela época. Ao longo da história europeia, os projetos anfictiônicos desapareceram por longos períodos, mas reapareceram em outras épocas sem perder, no entanto, seus traços fundamentais, como por exemplo, a busca e a garantia da paz e a solução pacífica dos conflitos. Tais princípios sempre foram norteadores para as iniciativas

\footnotetext{
${ }^{2}$ Nascido no México, Gérman Adolfo de la Reza é professor pesquisador da Universidade Autônoma Metropolitana-UAM, Unidade Xochimilco. Com formação e experiência em pesquisa no tema da Integração latino-americana, ocupou as cadeiras "Andrés Molina” da UAM-México, "Simón Bolívar" da Universidade de Paris e a cadeira de "Estudios mexicanos" na Universidade de Toulouse. Possui doutorado em Filosofia e História pela Universidade Toulouse La Mirail e em Ciências Econômicas pela Universidade de Paris I. Foi pesquisador da Universidade de Estocolmo e da Universidade Autônoma Nacional do México. É autor de inúmeras publicações sobre os temas da integração dos países latinoamericanos e os ciclos confederativos na América. Organizou e publicou os documentos sobre os movimentos de integração latino americanos do século XIX, bem como, sobre a obra intelectual e política de Simon Bolívar.
} 
unionistas, cujos objetivos são assegurar a segurança dos povos mediante a celebração de acordos de não agressão, o respeito mútuo entre os países, a formação de exércitos comuns e permanentes, a observação irrestrita por parte de cada membro do princípio de não intervenção nos assuntos internos de cada nação e a inviolabilidade das fronteiras territoriais, além de fomentar acordos comerciais e de navegação, entre outros pontos.

Esses princípios e objetivos, quando observados e compartilhados por seus signatários tendem a estabelecer o equilíbrio das relações entre os Estados-partes. Quanto maiores os graus de institucionalização jurídica e burocrática no interior dos Estados-partes, maiores serão as possibilidades de prever os comportamentos dos governos dos países e melhores serão as condições para a celebração de acordos e tratados. Por sua vez, na base das relações interestatais entre nações soberanas que partilham níveis semelhantes de organização e estabilidade interna está o Estado, alicerce para a formação de conjunturas internacionais equilibradas e duradouras (CASTRO, 2012, p. 36).

Nessa perspectiva, desde os tratados de união e liga das cidades-estados da antiguidade até os acordos de paz e cooperação internacional do período contemporâneo, o principal desafio para as nações interessadas na celebração de convenções interestatais é a organização interna de institutos de direito permanentes e estáveis. A experiência histórica nos informa que a anomia no interior das nações privilegiou mais as guerras do que a manutenção da paz. Um dos problemas era, portanto, estrutural. Até meados do século XIX, o juízo e o poder dos reis eram praticamente os únicos instrumentos de regulação e força do Estado. Cenários de instabilidade, desconfiança e hostilidade que, invariavelmente, favoreciam a guerra e inibiam a celebração e a manutenção da paz no contexto internacional eram resultado, em grande parte, das alterações de humor dos soberanos e da ausência de sistemas jurídico-formais consolidados e eficientes. Apesar dos primeiros ensaios constitucionalistas terem ocorrido no início do século XIX, as condições para eliminar as disputas que provocavam a "destruição das casas e das fortunas dos países", isto é, as guerras, ainda não eram suficientemente fortes (BECKER, 2013, p. 89).

Na América, as tentativas de integração das nações ocorreram a partir do início do século XIX. Inspirados nas anfictionias da antiguidade e nos princípios integracionistas divulgados nos séculos XVII e XVIII na Europa, os congressos latino-americanos elaboraram convenções jurídico-formais baseadas no direito internacional e no princípio da arbitragem. Muitos governantes e lideranças políticas promoveram princípios e implementaram ações para formação de órgãos e instituições supranacionais com o objetivo de viabilizar a cooperação entre os países, fortalecer o respeito mútuo, garantir as autonomias nacionais e a afirmação das identidades sociais e culturais, fomentar o livre comércio etc. A consolidação da paz, assentada na arbitragem internacional e na resolução pacífica dos conflitos requeria a celebração de tratados de direitos e deveres internamente consolidados em cada uma dos países confederados. Se de um lado, a garantia das independências 
políticas das antigas colônias da América dependia dos tratados de união e liga, de outro, a integração dos países dependia da consolidação dos institutos de direito no interior de cada nação.

Iniciados por Símon Bolívar (1783-1830), os esforços de integração latino-americanos se estenderam por pelo menos cinquenta anos, desde 1826 até 1865. Essas datas marcam a realização do primeiro Congresso do Panamá e do segundo Congresso de Lima, no Peru, respectivamente. As condições conjunturais em que ocorreram esses encontros eram imensamente distintas, mas os anseios e princípios eram praticamente os mesmos e foram amplamente inspirados nas antigas anfictionias do ocidente.

Os objetivos desse trabalho são descrever os principais aspectos que configuraram o Ciclo Confederativo latino-americano e analisar os estudos sobre o tema da integração na América a partir da perspectiva singular do historiador mexicano Gérman Adolfo de la Reza. Na primeira parte do texto, apresentamos algumas possibilidades de compreensão do termo anfictionias e as principais iniciativas de integração das nações na Europa dos séculos XVII e XVIII. Na segunda parte descrevemos como as iniciativas de integração europeias influenciaram Símon Bolívar e ensejaram o ciclo confederativo latino-americano. Na terceira parte destacamos os principais elementos que nortearam a primeira assembleia de nações da América, o Congresso do Panamá de 1826. Finalmente, antes das considerações finais, na quarta parte desse artigo apresentamos alguns dos aspectos que deram causa ao fracasso da primeira iniciativa unionista inaugurada na América em 1826.

\section{Os projetos anfictiônicos e a integração das nações da Europa}

Gérman Adolfo de la Reza nos apresenta um panorama bastante detalhado sobre a evolução das anfictionias na Europa e sobre o desenvolvimento dos projetos de união e liga de nações, os quais alcançaram inclusive a América. Vários trabalhos do historiador mexicano merecem destaque. No livro, A invenção da paz: Da República Cristã do duque de Sully à Federação das Nações de Simón Bolívar (REZA, 2015), Reza analisa a trajetória das iniciativas anfictiônicas propostas pelos pensadores europeus para o ocidente e seus principais desdobramentos históricos. Já no livro, El Ciclo Confederativo: historia de la integración latinoamericana del siglo XIX (REZA, 2012), o autor descreve a atuação dos representantes dos países latino-americanos e seus esforços para consolidar as independências das antigas colônias e a paz entre as nações a partir da celebração de tratados unionistas. 
Em um terceiro trabalho (DOCUMENTOS..., 2010), o pesquisador reuniu os documentos sobre o ciclo confederativo latino-americano tais como, correspondências trocadas pelos líderes das nações, as cartas convites enviadas aos países para realização dos congressos plenipotenciários e os tratados de união e liga celebrados nos congressos anfictiônicos que ocorreram na América entre 1826 e 1865. Em todas essas obras, Reza avalia o papel desempenhado por Símon Bolívar nos processos integracionistas, destacando suas influências e expectativas.

Ao se depararem com os movimentos de integração interestatais, como os latinoamericanos do século XIX por exemplo, pesquisadores de diferentes áreas podem encontrar dificuldades para compreender e lidar com um conceito em especial. Trata-se do termo, "anfictionias". Embora sua origem esteja relacionada a uma lenda da antiguidade grega, o conceito firmou-se como sinônimo de união e liga de nações.

Segundo a lenda, a primeira liga foi organizada por Anfictião, filho de Prometeu, um dos heróis míticos da Grécia, e fazia parte de uma assembleia onde eram aprovadas as regras de segurança e de vinculação recíproca, incluindo a proteção dos santuários e a celebração de ritos e jogos esportivos. A sua mensagem era a mesma que a das anfictionias posteriores: fazer menos frequentes as guerras através de acordos que apelavam à comunidade de interesses dos confederados, sua continuidade geográfica e à identidade cultural, religiosa e sanguínea dos seus habitantes (REZA, 2015, p. 11).

Constantemente ameaçados por invasões, os povos da antiguidade costumavam unir-se em confederações, privilegiando a religião como elemento de integração. Cidades-estados como Atenas e Delfos, a primeira, berço político da Grécia Antiga e a segunda, centro religioso onde estava localizado o santuário de Apolo, sustentaram anfictionias importantes baseadas na democracia e na religião. O objetivo era reunir os povos e formar ligas de cidades para combater inimigos externos como os persas e garantir a paz entre as cidadesestados da região. Atenas e Esparta conseguiram criar e manter ligas mais ou menos estáveis e duradouras, como a Liga de Delos e a Liga do Peloponeso. As rivalidades entre essas cidades, no entanto, provocavam inúmeros conflitos e em várias oportunidades precipitavam os povos para as guerras. As conflagrações entre essas ligas ou entre as cidades que integravam uma mesma liga, só encontravam termo quando invasores mais poderosos ameaçavam dominá-las. Nesses momentos, as ligas se uniam para combater os inimigos que colocavam em risco a segurança e a sobrevivência das populações (GOBBI, 2001, p. 159-160). 
As anfictionias gregas consolidaram o conceito. Por definição, as anfictionias são movimentos de união e liga de nações com o objetivo de manter a paz e melhorar as relações entre os países e suas populações. Movimentos de natureza anfictiônicos são, portanto, comuns desde as primeiras ligas da antiguidade grega, mas, apareceram em outros momentos da História Política do Ocidente, sobretudo nos mais difíceis e conturbados, como por exemplo, em períodos de guerras e graves crises. Nos séculos XVII e XVIII, após vários conflitos assolarem a Europa em função de intensas disputas políticas e religiosas, os projetos anfictiônicos passaram a despertar o interesse de personagens importantes como Maximiliem de Béthune, o duque de Sully, Charles Irenée de Castel, o abade de Saint-Pierre, Eméric Crucé, Hugo Grócio, Ernesto de Hesse-Reinfels, Pierre Nicole, Willian Penn, Jean Jacques Rousseau, Immanuel Kant e outros. Esses pensadores defendiam com entusiasmo as anfictionias e divulgavam amplamente seus pressupostos.

Os movimentos de integração e o ciclo confederativo latino-americano do século XIX possuíam forte inspiração nos movimentos anfictiônicos da antiguidade grega e nos trabalhos dos tratadistas europeus dos séculos XVII e XVIII. Essa assertiva é a grande contribuição de Gérman de la Reza para os estudos sobre as iniciativas unionistas nas antigas possessões hispânicas. Ao analisar os documentos produzidos pelos líderes das nações da América, principalmente os escritos por Símon Bolívar, suas leituras, correspondências e orientações aos ministros plenipotenciários, bem como, os tratados elaborados nos congressos, Reza identificou os traços que revelam as influências europeias nas propostas de união e liga dos países latino-americanos.

Segundo Reza (2015), a primeira grande influência é a do célebre Maximiliem de Béthune, o duque de Sully, que escreveu e editou os primeiros volumes das Memórias das sábias e reais economias do estado, domésticas, políticas e militares de Henrique o Grande, por volta de 1639 e 1640 . No trabalho, o duque de Sully redigiu um ousado plano para solucionar os conflitos entre as nações europeias do século XVII. Em suas cartas ao rei, o duque defendia que as nações cristãs da Europa deveriam se agrupar em uma confederação pacífica e religiosamente tolerante, a qual deveria trabalhar para estabelecer e manter o equilíbrio social, político e diplomático entre seus integrantes. O respeito e a defesa da nacionalidade de cada nação, entendidos pelo reestabelecimento das fronteiras e pela busca da paridade militar, econômica e territorial dos confederados figuravam entre os principais pontos de suas propostas. Além disso, o duque de Sully propôs ainda, que

[...] o mecanismo destinado a selar a paz entre os associados é a arbitragem internacional, administrado por um congresso de comissários renovável a cada três anos, cujas funções gerais englobavam a análise e a proposta de soluções para os temas básicos da confederação (REZA, 2015, p. 24). 
Em seu projeto de Paz, Charles Irenée de Castel, o abade de Saint-Pierre - Projeto para fazer a paz perpétua na Europa (1712-1717) enfatizou a necessidade de formação de uma confederação permanente e perpétua de Estados europeus, tomando como exemplo a união das nações alemãs. Para o abade, a ausência de um ente unificador, ou seja, uma assembleia de países capaz de gerir tratados de direito internacional e estabelecer um sistema de paz e unidade inalteráveis, dificultava o entendimento político entre as nações precipitando-as, quase sempre, para a guerra. Saint-Pierre sublinhou que a não intromissão de uma nação sobre os assuntos internos de outra nação e o reconhecimento e a aceitação do status quo territorial deveriam estar entre os pontos prioritários dos processos de integração regional. Contudo, a obra escrita pelo abade, extensa e difusa, tornava difícil sua compreensão, apesar de sua grande importância (REZA, 2015, p. 61-68).

Escolhido para analisar e reescrever o Projeto de Paz Perpétua de Saint-Pierre, o filósofo genebrino, Jean-Jacques Rousseau publicou entre 1758 e 1761 os Extratos do projeto de Paz Perpétua do Abade Saint-Pierre e Os julgamentos dos Projeto de Paz Perpétua do Abade SaintPierre. Entre as conclusões de Rousseau, constavam a necessidade de criação de uma aliança perpétua e irrevogável entre os países, a formação de um congresso plenipotenciário com representantes indicados pelos governos, um regimento interno para as sessões deliberativas, arrecadação e utilização de recursos financeiros e materiais para as atividades da aliança, a garantia de posse e sucessão dos estados membros em seus territórios, a proibição do uso da força e de intervenção de uma nação em assuntos internos de outra nação etc. Entre outros aspectos, o projeto previa também a possibilidade de expulsão e proscrição dos aliados que infringissem as regras dos tratados ou que não seguissem e regulamentassem em seus países as deliberações das assembleias. Com a organização e crítica das obras do abade por Jean-Jacques Rousseau, os textos de Saint-Pierre tornaram-se bastante conhecidos e amplamente divulgados na Europa juntamente com os Extratos de Rousseau, entusiasta dos tratados união e liga entre as nações (REZA, 2015, p. 75-82).

Entre os mecanismos jurídico-formais propostos por Rousseau para a concretização dos projetos unionistas estão a constituição de uma confederação de nações - perpétua e irrevogável, a realização de encontros permanentes entre membros nomeados pelos governos com poder de deliberação sobre assuntos de interesse comum, o revezamento da presidência na direção dos trabalhos da liga e a possibilidade de expulsão e aplicação de sanções às nações que desrespeitassem as determinações da aliança. Símon Bolívar foi educado na Venezuela pelo humanista Símon Rodríguez, antes de embarcar para Madri e Paris para continuar seus estudos. Rodríguez, por sua vez, era um estudioso dedicado e um divulgador entusiasmado das obras de Jean-Jacques Rousseau na América. Bolívar recebeu essa influência e ficou impressionado com a importância dada por Rousseau aos projetos de 
natureza anfictiônicos. Entre os autores mais lidos por Bolívar, Rousseau estava entre os principais e o influenciou enormemente.

\section{Símon Bolívar e o Ciclo Confederativo latino-americano}

O ciclo confederativo latino-americano do século XIX nasceu durante as guerras de independência travadas contra a metrópole espanhola. Os movimentos de emancipação na América atingiram rapidamente dimensões regionais. Líderes como Símon Bolívar, Bernardo O’Higgins, Bernardo de Monteagudo, José de San Martín e outros, promoveram os movimentos de integração em meio as lutas pela independência. A questão da autonomia nacional esteve, desde o início, vinculada aos projetos de integração regional e foram erigidos a partir do enfoque em fatores identitários como língua, cultura e tradição; fatores geopolíticos, que definiam a região como resultado da ação beligerante de um inimigo externo e comum; e o enfoque genealógico, que descrevia o nascimento das nações hispanoamericanas como a história de lutas contra as agressões e o domínio da Espanha (RUIZ, 2014, p. 132).

Para implementar as ações unionistas na América, Símon Bolívar adotou como referência parte importante dos escritos produzidos pelos tratadistas europeus dos séculos XVII e XVIII.

\footnotetext{
Em "Observações sobre a história da Grécia" de 1749, Gabriel de Mably, o mesmo que tinha sugerido a Rousseau o trabalho de sintetizar as obras de Saint Pierre, apresenta as confederações helênicas como um compromisso entre "o amor a independência" das cidades-estados e a necessidade de se proteger como "um corpo poderoso e respeitado". Coincidência ou não, a ideia define, com exatidão, a mensagem que Bolívar procurará dar à anfictionia latino-americana (REZA, 2010, p. 117).
}

As concepções que Bolívar possuía das ligas anfictiônicas revelam as influências dessas leituras. Não são poucos os trechos dos documentos produzidos por Bolívar em que podemos verificar a presença de ideias que vão ao encontro do que defendiam Mably e Rousseau, para citar apenas esses dois. Nas documentações produzidas por Bolívar como as correspondências trocadas com outros líderes ou nas orientações para a organização do 
movimento de integração, as atribuições de cada ente, as instruções aos plenipotenciários, bem como, a elaboração dos artigos dos tratados e convenções, a presença dos pressupostos teóricos elaborados pelos tratadistas europeus aparecem constantemente.

As conexões com os pensadores europeus podem ser observadas amiúde. Em carta enviada ao Senhor Pedro Gual, Ministro Plenipotenciário de Gran Colômiba, em abril de 1826, Bolívar manifestou seu entusiasmo com o Congresso do Panamá e revelou algumas de suas predileções quanto aos conteúdos que deveriam constar nos tratados. O caráter permanente e perpétuo da união dos estados hispano-americanos e a assembleia de nações como árbitro na mediação de conflitos entre os países foram cuidadosamente sublinhados.

\begin{abstract}
Convengo con Vd. en que la asamblea de Panamá es absolutamente necesaria al bien y al reposo de la América, y tan penetrado estoy de esta verdad, que yo desearía que esta asamblea fuese permanente para que, sirviendo de arbitro en las diferencias que cada día han de suscitarse entre estados nuevos y vecinos, fuere el lazo que los uniese perpetuamente (CARTA..., 1826b).
\end{abstract}

Bolívar não vislumbrava outro modo de defender e consolidar as independências se não a partir da formação de uma confederação de países vinculadas a uma autoridade superior. Como sustentam Figueiredo e Braga (2017, p. 312), "Bolívar concebeu a América como uma comunidade política formada por diversas repúblicas e dirigida por uma autoridade supranacional".

Em 11 de março de 1825, Bolívar enviou uma carta ao General Francisco de Paula Santander informando o envio de dez ou doze mil homens para ajudar Santander a combater as forças francesas que se aproximavam da costa venezuelana. Na correspondência, não se absteve de avaliar quais eram, naquele momento, as melhores opções para "salvar a América".

Yo creo que se puede salvar la América con estos cuatro elementos: primero, un grande ejército para imponer y defendernos; segundo, política europea para quitar los primeros golpes; tercero, con la Inglaterra; y cuarto, con los Estados Unidos. Pero todo muy bien manejado y muy bien combinado, porque sin buena dirección, no hay elemento bueno. Además insto sobre el congreso del Istmo de todos los estados americanos, que es el quinto elemento (CARTA..., 1825). 
Bolívar insistia no valor elevado de um ente supranacional coordenando a ação das repúblicas unidas. $\mathrm{O}$ argumento estava fundamentado na perspectiva de Bolívar de que, somente um corpo organizado e coeso era capaz de enfrentar as potências europeias, não somente a antiga metrópole, mas também a França e as nações absolutistas agrupadas na Santa Aliança - Império Russo, Império Austríaco e o Reino da Prússia. O tratado elaborado pelos ministros plenipotenciários das repúblicas hispano-americanas no Istmo do Panamá porém, contrariou sua predileção.

Bolívar acreditava em uma unidade estreita, com atributos que modernamente podem ser chamados de supranacionais, enquanto o Congresso chegou a uma proposta intergovernamental, sem a cessão de parcela da soberania de cada estado-parte (FIGUEIREDO; BRAGA, 2017, p. 310).

As negociações na assembleia no Istmo do Panamá e, mais tarde, as tratativas dos chefes dos governos para aprovar os tratados nas câmaras de seus países vão revelar outras das divergências entre os representantes das repúblicas. As dificuldades de construção de acordos e alianças, produto das incontáveis controvérsias e de um período marcadamente complexo e conturbado, anunciavam os limites do congresso.

\section{O Congresso do Panamá de 1826}

Em 1826, reuniram-se os ministros plenipotenciários das nações hispano-americanas ${ }^{3}$ no Istmo do Panamá. Apesar de todas as dificuldades, Bolívar sempre acreditou nas boas possibilidades para criação de uma sociedade de nações articuladas em torno de um ente supranacional com o objetivo de garantir a paz e a defesa da liberdade resguardadas, na prática, por forças militares comuns. O Congresso do Panamá de 1826 possuía um grande potencial para consolidação da paz. Conforme argumenta Aleixo,

3 As nações hispano-americanas reunidas no primeiro congresso anfictiônico da América, o Congresso do Panamá, que ocorreu no Istmo do Panamá em 1826, foram a Gran Colômbia (atualmente Colômbia, Venezuela, Equador e Panamá), as Repúblicas Centro-americanas (atualmente Honduras, Guatemala, Costa Rica, El Salvador e Nicarágua), México e Peru. 
[...] os Congresso de Westifália de 1648 e de Viena de 1815, realizados depois das guerras dos Trinta Anos e de Napoleão, trataram das relações entre vencedores e vencidos. O Congresso do Panamá, celebrado no período de paz, procurou estabelecer os instrumentos de paz (ALEIXO, 2000, p. 171).

Entre 1815 e 1826 Bolívar empenhou-se com os membros de seu governo e com os líderes das outras nações na preparação do Congresso do Panamá. Ele enviou emissários para conquistar a adesão das demais nações latino-americanas e selar acordos de união e liga entre as nações. Acordos bilaterais de união e confederação foram assinados entre as repúblicas da Gran Colômbia e Peru, em 6 de junho de 1822 e com o Chile, em 21 de outubro de 1823. As Repúblicas Unidas do Rio da Prata, contrárias a formação de uma confederação de nações, assinaram acordos bilaterais de amizade com a Gran Colômbia. A Bolívia, por sua vez, assinou um tratado de união e liga em 1825. O México aderiu aos acordos bilaterais com a Gran Colômbia em 3 de outubro de 1823 e garantiu sua participação no Congresso do Panamá. Nesse ato, o México também celebrou com a Gran Colômbia uma aliança militar para combater os espanhóis que ainda ocupavam territórios latino-americanos (REZA, 2005, p. 9).

Observemos, de entrada, que todos los ensayos unionistas compreendidos entre 1822 e 1865 se referem a un solo esquema: el areópago o la confederación anfictiónica, régimen que sólo Hispanoamérica pone en aplicación y que no rebastará los limites de ese período. El objetivo central es el mismo: responder a la amenaza externa con el concurso de un ejército común y precaverse ante posibles guerras internas apelando a un congresso dotado de facultades arbitrales (REZA, 2012, p. 20-21).

A Espanha era, na ocasião, a principal ameaça externa aos processos emancipacionistas no novo continente e aos projetos unionistas de natureza anfictiônicos. Bolívar articulou apoios de outras nações e garantiu a ida ao Panamá de representantes da Grã-Bretanha, dos Países Baixos e dos Estados Unidos - os nomeados pelo governo americano não conseguiram, porém, participar das conferências em função do atraso de John Sergeant e do falecimento, em Cartagena, de Richard C. Anderson, nomeados pelo governo norteamericano. Embora tenha sido convidado, o Brasil recuou na última hora e o Imperador D. Pedro I suspendeu a ida do Senador Theodoro José Biancardi ao Istmo do Panamá. 
Bolívar alimentava a expectativa de consolidar uma aliança duradoura com a Inglaterra antes da realização do encontro no Istmo do Panamá. Em carta ao Sr. José Rafael Revenga, de 11 de fevereiro de 1826, por ocasião dos preparativos para o congresso, Bolívar ressaltou a importância do apoio dos ingleses e das vantagens que todos os confederados da América poderiam desfrutar com uma aliança com a Grã Bretanha.

Por ahora me parece que nos dará una grande importancia y mucha respetabilidad la alianza de la Gran Bretaña, porque bajo su sombra podremos crecer, hacernos hombres, instruirnos y fortalecernos para presentarnos entre las naciones en el grado de civilización y de poder, que son necesarios a un gran Pueblo (CARTA..., 1826a).

Mas, imediatamente advertiu sobre os perigos de estabelecer uma relação com uma força tão poderosa.

\footnotetext{
Pero estas ventajas no disipan los temores de que esa poderosa nación sea en lo futuro soberana de los consejos y decisiones de la asamblea: que su voz sea la más penetrante, y que su voluntad y sus intereses sean el alma de la confederación, que no se atreverá a disgustarla por no buscar ni echarse encima un enemigo irresistible. Este es, en mi concepto, el mayor peligro que hay en mezclar a una nación tan fuerte con otras tan débiles (CARTA..., 1826a).
}

A chegada dos primeiros ministros plenipotenciários aconteceu em 21 junho de 1825. Entretanto, a instalação da assembleia aconteceu somente um ano depois, em 22 junho de 1826 na sala capitular do convento de las monjas de la Concepción. Os trabalhos foram, pelo menos em parte, dificultados pelos problemas de infraestrutura do local escolhido, o Istmo do Panamá, mas, tiveram início com os seguintes representantes dos seguintes países: Antonio Larrazábal e Pedro Molina, pela República Centro Americana; Pedro Gual e Pedro Briceño Méndez, pela Gran Colômbia; Mariano Michelena e José Domingues Manso, pelo México; José Maria Pando, Manuel Pérez de Tudela e Manuel Vidaurre, pelo Peru; John Sergeant, pelos Estados Unidos - que chegou ao Istmo com grande atraso; Edward Dawkins, pela Grã-Bretanha; e Jan Verveer, pelo países Baixos. Os três últimos participaram do 
Congresso do Panamá de 1826 na condição de observadores pelos países neutros, enquanto os demais, participaram na condição de plenipotenciários dos países confederados.

O resultado do encontro foi a elaboração do "Tratado de Unión, Liga Y Confederación perpetua de las Repúblicas de Gran Colombia, Centroamérica, Perú Y Estados Unidos Mexicanos, de 15 de Julio de 1826". Os princípios estabelecidos pelas nações confirmaram-se no tratado, isto é, a inviolabilidade da união a partir da celebração de um pacto perpétuo de amizade, respeito e defesa da soberania e da independência de cada uma das potências confederadas, da obrigação de auxílio mútuo, da proteção dos territórios e riquezas a partir da formação e do emprego de contingentes de tropas marítimas e terrestres em toda e qualquer situação que implicasse agressões, invasões ou qualquer ato de agravo que ferisse a integridade das nações unidas (REZA, 2010, p. 210).

$\mathrm{O}$ artigo 13 do Tratado definiu que a negociação de qualquer acordo bilateral ou conjunto, deveria buscar níveis mutuamente satisfatórios para todas as nações confederadas, contribuir para a manutenção da paz e da amizade, possibilitar a conciliação e a mediação pacífica de toda e qualquer questão entre as potências confederadas ou estrangeiras. Em casos de guerras com outras nações, atingir o mais rápido possível a celebração de acordos que acelerassem o fim das hostilidades e selassem a paz. As nações se obrigavam ainda a não celebrar separadamente ou sem conhecimento dos demais confederados, acordos com países que não integravam a aliança. Todavia, caso não fosse possível a celebração de acordos de todos os países confederados com qualquer nação estrangeira, estava garantida a liberdade de celebração isolada ou em separado de acordos de união e aliança entre um ente confederado e outro país (REZA, 2010, p. 213).

O tratado obrigava as nações confederadas a consultar a assembleia todas as vezes que julgasse ter recebido, por parte de qualquer um dos países da confederação, atos de agravo ou agressão. Para esses casos, previa o artigo 17, "sean cuales fueren las causas de injurias, daños graves u otros motivos que alguna de las Partes Confederadas pueda producir [...] ninguna de ellas podrá declararles guerra [...] sin levar antes su causa [...] a la decision conciliadora de la Asamblea" (REZA, 2010, p. 214). Cabia a Assembleia Geral de Ministros Plenipotenciários dirimir os conflitos e prover solução às causas entre os litigantes. Um dos aspectos fundamentais do acordo estava previsto no artigo 19 do Tratado, que previa a expulsão sumária da nação confederada que, em qualquer circunstância e sob qualquer justificativa, desrespeitasse as decisões das assembleias.

Notemos que até aqui, os acordos celebrados pelas nações latino-americanas traziam muitos traços que haviam sido informados anteriormente pelos grandes tratadistas europeus. Como salienta Gérman de la Reza (2015, p. 16), "os espíritos ilustrados do continente promoveram a criação de instâncias de arbitragem e confederação, através de projetos de corte pacifista ou religioso" e de natureza anfictiônicos, orientados pelos pensadores do Velho Mundo. Havia pois, um conjunto de princípios de natureza anfictiônica 
que deveria compor invariavelmente os tratados de união e liga das nações. Desde a antiguidade, passando pelos tratadistas europeus dos séculos XVII e XVIII e alcançando a América da primeira metade do século XIX, as convenções de nações orientaram-se pela busca e manutenção da paz, segurança coletiva, defesa recíproca, independência política e integridade territorial. Sem esses aspectos, era impossível construir e celebrar tratados de integração interestatais.

Embora tenham aprovado diretrizes para uma quantidade considerável de temas, alguns pontos, considerados mais difíceis, não foram resolvidos pelos plenipotenciários. As discussões para contemplar o artigo 22 do tratado, que definia o estabelecimento das fronteiras e a demarcação territorial seguindo as referências das delimitações de 1810, não prosperou. Os rumos das conversações sobre o tema dos limites territoriais entre os países membros se transformou em terreno instável, tendo em vista a particularização excessiva das disputas. Conforme demonstram as atas das discussões, o tema sempre esteve entre os mais áridos, e talvez por isso, tenha recebido tratamento diferenciado pelos tratadistas.

Centroamérica reclama a México el território de Chiapas Y a Colombia las costas de Mosquitos; el Perú, a sua vez, considera injusta la pértida de Guayaquil y no reconoce el año de 1810 como punto de partida para la aplicación del uti possidetis. A medida que los reclamos territoriales encontram los ánimos de los delegados, la Asamblea decide transferir el problema de las fornteras a las convenciones particulares que los países establezcan en el futuro (REZA, 2005, p. 12).

O ponto que envolvia a formação de forças militares comuns foi resolvido com a deliberação favorável à formação de uma força militar composta por 60 mil homens e com o objetivo de combater "su enemigo común el Rey de España" (REZA, 2010, p. 220-224). Foram retiradas do Tratado, no entanto, as propostas de apoio a independência de Cuba e Porto Rico ou qualquer empreendimento militar para liberar as ilhas. Na avaliação dos ministros plenipotenciários, precipitar-se sobre o Caribe poderia inviabilizar qualquer tratativa para obter um armistício com a Espanha. Além disso, uma nova frente de guerra com a nação ibérica tornaria ainda mais vulnerável a situação das nações confederadas e abriria espaços para que os Estados Unidos se envolvessem nos conflitos e acabassem por estabelecer seu domínios sobre a região (REZA, 2012, p. 97).

O Congresso do Panamá de 1826 produziu uma quantidade considerável de documentos. Apesar dos avanços nas negociações bilaterais e conjuntas, o evento não foi capaz de sedimentar, porém, as bases para que a confederação avançasse nos parlamentos de cada 
um dos países. $\mathrm{O}$ fracasso da união ocorreu principalmente em função das dificuldades que os ministros plenipotenciários e os governantes tiveram para conduzir as negociações nas câmaras de suas nações. As desconfianças e resistências que persistiram entre uma nação e outra e a ação desestabilizadora que os Estados Unidos promoveu com o intuito de inviabilizar o projeto produziram efeitos devastadores para a liga. Como salientou José Briceño Ruiz (2014, p. 137),

\footnotetext{
Al cerrarse el ciclo de las guerras de independência, los países de la América Hispana iniciaron um periodo caracterizado, por um lado, por la inestabilidad interna y guerras civiles $\mathrm{y}$, por el outro, por las intervenciones y agressiones externas. Las primeiras de estas últimas aparecen em la década de 1830 y a diferencia de los temores existentes em la década anterior, no provenían de la España.
}

A partir da década de 1830, afastadas as ameaças da coroa espanhola, os países da América-hispânica passaram a ocupar seu tempo com as incursões cada vez mais agressivas da Inglaterra e da França - que disputavam possessões e influências no sul do continente - e seu vizinho mais poderoso, os Estados Unidos. Este último apoiou colonos anglo-saxões a proclamar a independência do Texas em 1835 e investiu sobre os territórios mexicanos do Novo México e da Califórnia, na década de 1840. O governo norte-americano também instruiu e apoiou invasões na América Central com o intuito de desestabilizar uma região que ainda se encontrava bastante fragilizada pelas guerras civis e secessões das repúblicas Centro-americanas.

\section{O malogro do processo de integração latino americano}

Apesar de bastante ambiciosos e dos horizontes até certo ponto distantes ou supostamente inalcançáveis, é possível, a partir da análise dos documentos sobre as iniciativas unionistas na América compreender as dificuldades e as limitações que permeavam os esforços de integração na América do século XIX. Como sublinha o professor Gérman de la Reza, "En oposición a una ideia común de los historiadores, esto sugere que el Congresso del Panamá no fue utópico ni prematuro, sino que llegó tardiamente, en momentos en que la complejidad y los costos de revertir el sentido centrífugo de las fuerzas en pugna eram muy elevados." (2012, p. 21) 
O primeiro grande ponto de desavença e que desencadeou grande disputa entre os ministros plenipotenciários estava na apresentação e reclamação da autoria do primeiro projeto de constituição do tratado de liga. Os ministros do Peru haviam elaborado uma proposta inicial para o tratado de confederação das nações ${ }^{4}$, mas a discussão do projeto peruano foi habilmente esvaziada pelos ministros colombianos. Segundo Pedro Briceño Méndez, ministro plenipotenciário da Gran Colômbia, o projeto peruano não fora redigido corretamente, além de conter inúmeros pontos alheios ou que não estavam de acordo com os objetivos do congresso de união e liga das nações. A partir daí, ficou acordado que os representantes da Gran Colômbia, da República Centro-americana e do México apresentariam uma contraproposta, elaborada em conferências em separado. $O$ novo documento tornou-se base para o tratado e foi praticamente o mesmo projeto aprovado em 15 de Julho de 1826 (REZA, 2010, p. 231-232).

A transferência da sede do Congresso do Istmo do Panamá para a vila mexicana de Tacubaya gerou grandes controvérsias. $\mathrm{O}$ artigo 31 do Tratado de Liga e União celebrado pelos membros do Congresso em 15 de Julho de 1826 no Panamá definiu a mudança do local da sede, gerando insatisfações consideráveis entre os representantes da Gran Colômbia. Em seu relatório enviado a Bolívar, o ministro plenipotenciário Pedro Briceño Méndez apontou que um dos fatores que indicavam que os tratados firmados no congresso do Istmo não prosperariam era de que o México não desejava de fato uma liga perpétua, mas tão somente uma união transitória que durasse até o término das guerras com a Espanha. As intenções do México eram tão somente solucionar, com a ajuda de seus vizinhos latino-americanos, com ou sem um tratado de união, seus problemas de curto prazo e, ao alcançar êxito em seus intentos, abandonariam a confederação (REZA, 2010, p. 235-236).

As desconfianças dos membros da confederação em relação as pretensões imperialistas de Bolívar também são apontadas como causa para o fracasso da primeira iniciativa anfictiônica na América. Diante disso, os representantes dos outros países passaram a fazer resistência a Gran Colômbia, lançando mão de estratégias que estivessem ao alcance para anular a liderança dos colombianos. Entre as estratégias, o expediente de mudar a sede do congresso, levando-o para uma lugar em que Bolívar não tivesse nenhuma influência, tornou-se uma necessidade de primeira ordem. Bolívar percebeu o movimento, mas aceitou o argumento oficial de que a insalubridade do Istmo e as dificuldades de comunicação com os governos justificavam a mudança: "como lo había advertido Santander, la falta de salubridad se convierte en un problema mayor (REZA, 2006, p. 75-76).

Em 2 de março de 1827, Manuel Vidaurre, Ministro das Relações Exteriores do Peru ordena ao representante de seu país na assembleia que abandone o congresso e retorne imediatamente ao país. Com essa medida, Vidaurre declarou abertamente sua oposição a

\footnotetext{
${ }^{4}$ Documento $\mathrm{N}^{\circ}$ 37. Proyecto de Tratado Presentado por la Delegácion de Perú en la inauguración del Congresso. Panamá, 22 de Junio de 1826. (DOCUMENTOS..., 2010, p. 166-167).
} 
Bolívar, além de liderar parte das tropas peruanas na ocupação da Colômbia em 1829. Coincidentemente, o fim dos esforços de união e liga das nações iniciado no Panamá em 1826 e concluídos em Tacubaya em 1827, inauguram uma nova fase de conflitos em quase todos os países da região. Em 1828, além da guerra da Gran Colômbia contra o Peru, Bolívar teve que enfrentar rebeliões internas que culminaram com a separação da Venezuela e do Equador. Na República Centro-americana, uma guerra civil resultou na formação da Guatemala, Honduras, Nicarágua, El Salvador e Costa Rica. No México, dissensões internas entre grupos rivais, as constantes investidas da Espanha e as disputas territoriais com os Estados Unidos alteraram profundamente as prioridades do governo do Presidente Guadalupe Victoria, até então, um entusiasta da união ao lado de Bolívar.

Os conturbados processos que envolviam os povos da América-hispânica, principalmente os movimentos emancipacionistas e, mais tarde as guerras de secessão, absorveram muitas energias e recursos. Como salienta Halperín Donghi, em 1825, com o fim dos processos de emancipação, restaram destruídas partes importantes da estrutura colonial. Ainda que severamente contestadas e criticadas pelos colonos durante os longos períodos que antecederam as independências, as estruturas econômicas, sociais e institucionais das antigas colônias garantiam, de um modo ou de outro, alguma estabilidade, ainda que precária, às relações e negócios entre os colonos e a metrópole. Parcialmente dissolvidas pelas guerras de independência, as estruturas antigas mantiveram porém, seu caráter elitista regionalizado. Prova disso é a prevalência das elites crioulas na condução da política e dos negócios dos novos países (DONGUI, 2005, p. 135).

A formação das novas nações demandava constantemente quadros de pessoal cada vez maiores para compor os governos, dar conta da burocracia, formar as assembleias, edificar novas instituições ou reavivar as antigas, o que servia para aglutinar, ainda que precariamente, indivíduos e grupos. $O$ rearranjo dos mercados internacionais e a integração das colônias a esses mercados, estabelecia limites para as disputas internas, mas não amenizava os conflitos. Segundo Halperín Donghi, a estabilidade social e política não foi imediatamente alcançada após as independências, mas certamente ocorreram acomodações importantes para amenizar as disputas à medida que as relações das colônias com as zonas de comércio metropolitanas foram minimamente reestabelecidas (DONGUI, 2005, p. 209).

Não é prudente concentrar a compreensão de cenários essencialmente complexos em um único aspecto do contexto analisado, como o econômico por exemplo, uma vez que outros elementos também possuem grande influência sobre os contextos. As dissensões no interior das nações forçavam "para baixo", ou seja, colocavam obstáculos e impunham limitações severas à ação dos governos. Muitas eram as forças operando para impor barreiras aos esforços de confederação das nações da América-hispânica. Forças centrífugas operavam internamente em cada país produzindo divergências e desconfianças e, consequentemente, severos danos ao progresso dos movimentos anfictiônicos. 
Imbuídos de sua missão libertadora, parte das elites instaurou modelos políticoinstitucionais cujas bases se assentavam no republicanismo e no constitucionalismo, mas também, na centralização das instituições de Estado e no militarismo. A perseguição aos antigos representantes da metrópole e a disposição beligerante dessas forças, ampliou a resistência dos grupos locais que se sentiam cada vez mais alijados do poder. Desse modo, as elites regionais passaram a atuar fortemente para ocupar os parlamentos de seus países e barrar os ímpetos centralizadores dos governos. Quando não conseguiam participar da política, a luta armada era o meio de atuação mais adequado. A militarização desses grupos fez surgir o que José Murilo de Carvalho denominou "pequenos bonapartes", lideranças locais sempre dispostas a confrontar o centro ou fazer carreira em revoluções e sedições (CARVALHO, 2003, p. 169).

Não foram poucas as tentativas dos conferencistas e dos presidentes das nações, principalmente Guadalupe Victoria do México, para que as casas legislativas de seus países ratificassem os acordos. Victoria chegou a suplicar aos congressistas mexicanos que concluíssem os debates com vistas a aprovação dos tratados. Contudo, desde a instalação da assembleia em Tacubaya em 1827, era notório o desprezo da maior parte dos deputados e senadores mexicanos pelo movimento de união e liga das nações. Os ministros plenipotenciários Pedro Gual e Antonio Larrazábal, relataram na última reunião da assembleia plenipotenciária de Tacubaya, em 9 de outubro de 1827, que ambos estavam convencidos, após o fracasso das ratificações dos tratados nas casas legislativas daquele país, que o México, de fato, nunca teve interesse nas negociações em trânsito, nem tão pouco na formação de uma confederação de países latino-americanos, com exceção de seu presidente, Guadalupe Vitória (REZA, 2012, p. 127-128).

O quadro interno foi agravado pelas pressões e intervenções externas. O interesse dos Estados Unidos, desde o convite para enviar observadores até o início das reuniões no Panamá em 1826, transitou do entusiasmo para a aversão velada. A preocupação dos norteamericanos com a força comercial dos ingleses na região motivou o presidente John Quincy Adams a enviar representantes ao Panamá. Mas, a medida que as conversações evoluíam, as orientações aos delegados dos Estados Unidos passaram a focar essencialmente na defesa dos princípios da Doutrina Monroe. Sob o lema "a América para os americanos", os Estados Unidos visavam estabelecer-se como o protetor dos países latino-americanos. Nesse sentido, era importante inviabilizar os tratados de união, liga e confederação, sobretudo o desejo de seus proponentes de criar um ente supranacional com poderes arbitrais. Eles temiam acima de tudo que os conflitos fossem resolvidos por uma instituição que concentrasse tais poderes, suplantando as pretensões protecionistas e intervencionistas dos Estados Unidos. Desse modo, os norte-americanos trabalharam para transformar o projeto anfictiônico em um tratado de comércio e navegação, esvaziando o caráter arbitral da assembleia de nações (REZA, 2012, p. 114). 
É preciso abordar, ainda que resumidamente, a situação do Brasil no Congresso Anfictiônico do Panamá. Em 1826, as vésperas do congresso, o Imperador Dom Pedro I cancelou sua ida, bem como, o envio de representantes brasileiros sem apresentar qualquer justificativa ou motivo alegado. O Imperador brasileiro avaliou, porém, que sua participação no congresso pudesse provocar algum mal estar diplomático com Madri. A relações de parentesco de Dom Pedro I com o regente da Espanha, D. Fernando VII, tornavam o Brasil, na visão dos ministros plenipotenciários e dos governantes dos países latino americanos, um potencial inimigo às causas emancipacionistas. Ao invés do Imperador do Brasil trabalhar para se tornar um conciliador nas negociações que envolviam a Espanha e as nações da América, ele preferiu o isolamento e declinou do convite das nações hispanoamericanas. Mesmo após ter nomeado o Ministro do Conselho Imperial, Thedoro José Biancardi, o Imperador cancelou a participação do Brasil.

O Brasil não era declaradamente um oposicionista das independências latinoamericanas, nem tão pouco dos projetos anfictiônicos. Antes da Proclamação da Independência do Brasil em 1822, o Ministro dos Negócios Estrangeiros e da Guerra do Reino Unido de Portugal, Brasil e Algarve, Silvestre Pinheiro Ferreira, elaborou e propôs a formação da uma confederação dos povos agredidos. De modo semelhante, José Bonifácio de Andrada e Silva defendeu, também em 1822, uma proposta de união anfictiônica para combater e fazer frente às pretensões europeias, mediante a formação de uma "Liga Ofensiva e Defensiva entre os Estados da América" com o objetivo de fortalecer as defesas dos países independentes e fomentar livre comércio. Tanto a proposta de Ferreira quanto a de Bonifácio não prosperaram, a exemplo do que ocorreu com a participação do Brasil no Congresso do Panamá em 1826, mas assinalaram as intenções de figuras importantes do governo em favor das anfictionias latino-americanas (ALEIXO, 2000, p. 174-175).

Os fatores que fizeram o Brasil desistir de sua participação no Congresso do Panamá de 1826 iam desde os esforços brasileiros para que as potenciais europeias reconhecessem a Independência até o litígio fronteiriço entre Brasil e Buenos Aires na Banda Oriental e entre o Brasil e a região de Chiquitos no Alto Peru. Em primeiro lugar, participar de um congresso de nações hispano-americanas recém emancipadas poderia afrontar a Espanha que, por seu turno, poderia impor obstáculos às pretensões do Brasil quanto ao reconhecimento de sua Independência. Em segundo lugar, as manifestações de apoio das repúblicas hispanoamericanas à causa de Buenos Aires e a forte contestação à ocupação de Chiquitos confrontavam a posição do Brasil em relação aos limites territoriais. Além desses fatores, o Brasil era uma monarquia constitucional em um continente em que todos os outros países eram repúblicas. No entendimento brasileiro, o congresso poderia servir como um mecanismo de pressão sobre os representantes do governo, apesar do tema não ter entrado nas pautas de discussão. Finalmente, a opção brasileira pelo sistema escravista, elemento veementemente combatido pelos representantes das repúblicas hispano-americanas, gerava, por si só, desgastes significativos (ALEIXO, 2000, p. 180). 
É importante frisar que o Brasil, seu regime monárquico, seu sistema escravista e suas pretensões expansionistas contrariavam todos os princípios e valores do projeto anfictiônico proposto pelos líderes das nações hispano-americanas. Bolívar e os defensores da causa integracionista defendiam o republicanismo e a abolição da escravatura, além da soberania das nações e solução pacífica dos conflitos. Todos esses elementos iam de encontro com as disposições beligerantes de uma nação que se autodenominava Império, fundamentalmente sustentado por um sofisticado sistema de hierarquias e divisões sociais, do poderio político das elites regionais, pela força de seu monarca e da casa que representava.

\section{Considerações finais}

Esse trabalho buscou apresentar os principais aspectos que configuraram o Ciclo Confederativo latino-americano a partir da perspectiva singular do historiador mexicano, Gérman Adolfo de la Reza. Singular, pois, Reza demonstrou em seus trabalhos como as anfictionias europeias dos séculos XVII e XVIII influenciaram as iniciativas de integração das nações da América do século XIX. De igual modo, explicou como os líderes dos países latino-americanos, entre eles Símon Bolívar, assimilaram as ideias e propostas dos pensadores europeus para elaborar tratados de união e liga no Novo Mundo. Com base em parte importante da vasta quantidade de documentos produzidos na América, Reza expôs os vínculos entre as iniciativas unionistas da América e as semelhanças entre os projetos europeus, além das visões e dos problemas envolvidos em propostas dessa importância. Juntamente com os trabalhos de Reza, buscamos em parte importante da historiografia e documentos da época, ampliar nossa compreensão sobre as trajetórias e dinâmicas do tema em questão.

O Congresso do Panamá de 1826 não alcançou, no entanto, os resultados imaginados por Bolívar e pelos demais apoiadores da integração interestatal na América. As possibilidades da associação cederam lugar à guerra e às dificuldades que os líderes dos países enfrentaram no ambiente doméstico para fazer prosperar o debate político em favor dos projetos de união. As discussões para formar uma confederação de países hispanoamericanos, tanto no Istmo do Panamá quanto na Vila de Tacubaya, no México, entre 1826 e 1827, aconteceram em um período em que as nações latino-americanas enfrentavam o auge dos desafios que envolviam a emancipação. Rondava a figura ameaçadora da metrópole que, na ocasião dos encontros, ainda exigia os direitos sobre suas antigas possessões. A estratégia de Bolívar e seus companheiros foi bastante inteligente. Para afastar os perigos da reocupação colonial, trabalharam para criar uma confederação de países que partilhavam, 
entre outros elementos, da mesma língua e tradições, mas, sobretudo, de um passado marcado pela dominação hispânica.

As disputas entre os países e a recusa das câmaras nacionais em referendar o conteúdo dos tratados contribuíram para inviabilizar as iniciativas de união e liga das nações na América. Nenhum país jamais se tornou signatário das deliberações dos congressos latinoamericanos produzidos no Congresso do Panamá. Os defensores da causa anfictiônica na América foram engolidos pelos interesses difusos dos países hispano-americanos do continente, pela resistência das forças políticas no interior de cada nação e, em última instância, pelas disputas entre as demais potências mundiais - leia-se Estados Unidos, Grã Bretanha e França - pelo domínio geopolítico e econômico da região.

O caráter integracionista das iniciativas de união e liga das nações, orientadas para estabelecer uma ordem jurídica-formal capaz de inibir os conflitos entre as países, privilegiar a mediação pacífica entre os litigantes e estabelecer a paz, princípios norteadores das ações unionistas latino-americanas do século XIX, falharam precocemente. A ausência de bases políticas consistentes no interior de cada uma das nações e de normativos legais consolidados, enfraqueceu os projetos e obstruiu os esforços de líderes como Símon Bolívar na Gran Colômbia e Guadalupe Vitória no México. Nem a consistência teórica dos tratadistas europeus dos séculos XVII e XVIII, nem as capacidades de liderança dos postulantes da causa hispano-americana foram capazes de evitar o fracasso melancólico do projeto unionista das novas nações da América. Todavia, é importante sublinhar que os tratados produzidos nos congressos anfictiônicos do século XIX serviram de base para os esforços de integração da América Latina no século XX.

\section{Referências}

ALEIXO, José Carlos Brandi. O Brasil e o congresso anfictiônico do Panamá. Revista Brasileira de Política Internacional, Brasília, v. 43, n. 2, p. 170-191, jul./dez. 2000. Disponível em: $<$ http://www.scielo.br/scielo.php?script=sci_arttext\&pid=S0034-73292000000200008>. Acesso em: 5 abr. 2017.

BECKER, Evaldo. Rousseau e os escritos sobre a paz perpétua, do Abade de Saint-Pierre: críticas e aproximações. In: CARMO, Corival Alves et al. Relações internacionais: olhares cruzados. Brasília: FUNAG, 2013.

CARTA de Símon Bolívar para el General Francisco de Paula Santander. Lima, 11 mar. 1825. 
<http://www.archivodellibertador.gob.ve/escritos/buscador/spip.php?article9932>. Acesso em: 27 fev. 2018.

CARTA del libertador Simón Bolívar a José Rafael Revenga sobre los preparativos del Congreso Anfictiónico de Panamá. Magdalena, 11 feb. 1826a. Disponível em: $<$ http://www.archivodellibertador.gob.ve/escritos/buscador/spip.php?article555>. Acesso em: 27 fev. 2018.

CARTA del libertador Simón Bolívar dirigida al Señor Pedro Gual, relacionada al Congreso de Panamá. Lima, abr. 1826b. Disponível em: <http://www.archivodellibertador.gob.ve/escritos/buscador/spip.php?article723>. Acesso em: 27 fev. 2018.

CARVALHO, José Murilo. A construção da ordem: a elite política imperial. Teatro de sombras: a política imperial. Rio de Janeiro: Civilização Brasileira, 2003.

CASTRO, Thales. Teoria das relações internacionais. Brasília: FUNAG, 2012.

DOCUMENTOS sobre el congreso Anfictiónico de Panamá. Caracas: Fundación Biblioteca Ayacucho y Banco Central de Venezuela, 2010.

DONGUI, Tulio Halperín. Historia contemporánea da América Latina. Madri: Alianza, 2005.

FIGUEIREDO, Alexandre Ganan de Brites; BRAGA, Márcio Bobik. Simón Bolívar e o Congresso do Panamá: o primeiro integracionismo latino-americano. Passagens. Revista Internacional de História Política e Cultura Jurídica, Rio de Janeiro, v. 9, n. 2, p. 308-329, maio/ago. $2017 . \quad$ Disponível em: $<$ http://www.historia.uff.br/revistapassagens/artigos_ing/v9n2a82017_ing.pdf $>$. Acesso em: 23 fev. 2018.

GOBBI, Hugo Javier. Integração e liberdade: uma reflexão histórica. Revista Brasileira de Política Internacional, Brasília, v. 44, n. 1, p. 154-164, jan./jun. 2001. Disponível em: <http://dx.doi.org/10.1590/S0034-73292001000100012>. Acesso em: 17 fev. 2018.

REZA, Gérman A. A invenção da paz: da república cristã do Duque de Sully à federação das nações de Simon Bolívar. Tradução de Jorge Adelqui Cáceres Fernández e André Figueiredo Rodrigues. São Paulo: Humanitas, 2015.

REZA, Gérman A. El ciclo confederativo: história de la integración latinoamericana el siglo XIX. Lima: Centro de Produción Fondo Editorial-Universidad Nacional Mayor de San Marcos, 2012. 
REZA, Gérman A. Más allá de la negligencia racional la Asamblae de Tacubaya, 1826-1828. Estudios de Historia Moderna y Contemporánea de México, Cidade do México, n. 30, p. 5-45, jul./dic. 2005. Disponível em: <http://www.historicas.unam.mx/moderna/ehmc/ehmc30/355.html>. Acesso em: 5 abr. 2017.

REZA, Gérman A. de. Documentos Sobre El Congreso Anfictiónico de Panamá. Germán A. de la Reza: preámbulo, prólogo y notas. Caracas: Fundación Biblioteca Ayacucho y Banco Central de Venezuela, 2010.

REZA, Germán A. de La. Congresso de Panamá de 1826 Y otros ensayos de integración latinoamericana en el siglo XIX. Estudios Y Fuentes Documentales Anotadas. México, D.F: Ediciones Y Gráficos Eón, 2006.

RUIZ, José Briceño. Los congresos hispanoamericanos en el siglo XIX: identidad, amenazas externas e intereses en la construcción del regionalismo. Revista de Relaciones Internacionales de la UNAM, México, n. 118, p. 131-170, ene./abr. 2014. Disponível em: <http://www.revistas.unam.mx/index.php/rri/article/view/51458/45985>. Acesso em: 21 fev. 2018.

Recebido em 10/06/2017

Aprovado em 06/03/2018 